Artigo - Apresentação

\title{
CIÊNCIA E RESISTÊNCIA: OS MOVIMENTOS SOCIAIS E OS DESAFIOS E POSSIBILIDADE PARA PRODUÇÃO DO CONHECIMENTO CIENTÍFICO
}

\author{
SCIENCE AND RESISTANCE: SOCIAL MOVEMENTS AND CHALLENGES \\ AND POSSIBILITY FOR THE PRODUCTION OF SCIENTIFIC KNOWLEDGE
}

\section{CIENCIA Y RESISTENCIA: MOVIMIENTOS SOCIALES Y DESAFÍOS Y POSIBILIDAD DE PRODUCCIÓN DE CONOCIMIENTOS CIENTÍFICOS}

\section{Helder Freitas do Bomfim}

O dossiê "Ciência e Resistência: movimentos sociais e a produção do conhecimento" é resultado da articulação de uma rede pesquisadores e militantes, que estão desenvolvendo estudos na área das Ciências Humanas sobre movimentos sociais na América Latina. A proposta surge como um projeto do Grupo de Pesquisa "Ciência e Resistência", vinculado ao Departamento de Ciências Humanas e Tecnologias - DCHT - Campus XVII da Universidade do Estado da Bahia - UNEB. A obra tem por objetivo apresentar pesquisas contemporâneas sobre a disputa política, cultural e científica, frente aos avanços e conflitos subjacentes da hegemonia do neoliberalismo. A produção do conhecimento sobre movimentos na América latina, em especial nas duas primeiras décadas do século XXI, apontam que, em um circuito de lutas globalizado, passamos por um momento de grandes transformações nas formas de organização da resistência. Assim como, há um processo de diversificação das abordagens e teorias para a interpretação do fenômeno, Ghon (2018). Vivemos um contexto de constante ressignificação de categorias operativas clássicas, situação que demanda a realização de constantes pesquisas para a compreensão das práticas organizadas de contestação.

Conforme salienta Jaumont e Varella (2016):

A pesquisa militante na América latina, não é, obviamente, uma
invenção dos autores que aqui escrevem. É, pelo contrário, um
acúmulo prático teórico ao longo da história, para o qual
contribuíram pensadoras, pensadores, militantes,
pesquisadores, intelectuais, movimentos sociais, organizações
políticas e coletividades, com suas reflexões, sonhos, ações e
vida. Representa, portanto, um patrimônio dos povos latino-
americanos em luta por dignidade em suas diversas dimensões.

Os trabalhos aqui reunidos apresentam resultados de pesquisas sobre movimentos sociais contemporâneos. Inquietações que se destacam por resultarem da articulação entre produção de conhecimento científico com acontecimentos recentes do Brasil. As reflexões apresentadas são produzidas em um contexto emblemático de avanço de forças conservadoras na política na América latina. Sobretudo no Brasil, pós-golpe parlamentar e impeachment da presidenta Dilma Roussef em 2016, prisão do ex-presidente Lula e vitória nas urnas em 2018 de Jair Bolsonaro com um projeto explicito de criminalização dos 
movimentos sociais. Esses textos se lançam em um contexto marcado por perseguições políticas e assassinatos de lideranças da esquerda, a exemplo o recente assassinato da Vereadora do Rio de Janeiro Marielle Franco e Moa do Katende líder comunitário soteropolitano. A produção dessa coletânea se destaca na contramão da complacência e subordinação acrítica que tanto enrijece as chances de transformação social.

De forma prática, resulta da vontade política de pesquisadores engajados em lutas sociais. E se lança, na direção de defesa e fortalecimento da ciência como estratégia para desenvolvimento. É de interesse da coletânea problematizar em perspectiva interdisciplinar sobre as potencialidades e desafios para objetivação de práticas insurgentes. Analisando as contribuições dos movimentos sociais para a transformação políticas e social do Brasil. As escolhas dos textos são frutos da necessidade de visibilizar a experiências em curso, em especial contribuições teóricas metodológicas para os estudos dos movimentos sociais na América latina.

De forma estratégica, reunimos autores que instigam importantes pontos de inflexão sobre desafios contemporâneos das formas resistência e de construção de ações coletivas. Os artigos, dialogam por se construírem por experiências científicas recentes, possibilitadas pela audácia intelectual de construção de pesquisas que questionam as formas tradicionais da escrita científica. Os textos aqui reunidos, provocam os leitores a aproximações com as epistemologias decoloniais, são produzidos o numa perspectiva crítica e engajada, e refletem sobre a prática da escrita acadêmica enquanto perspectiva política e metodológica para a produção de narrativas de si e da alteridade

O nosso ponto de partida é a pressuposição prática, política e ética da impossibilidade de conjunção entre fazer cientifico e neutralidade axiológica, debate antigo da filosofia do conhecimento e no no momento de avanço do conservadorismo, retoma-lo se faz necessário. Os textos apresentam trajetórias coletivas que redimensionam a relação entre saber, poder e transformação social através da produção científica. Para além de divagações idealistas, os autores aqui reunidos, além de militantes são pesquisadores cujas trajetórias acadêmicas despontam para o que chamamos aqui de narrativas insurgentes, ou melhor, ebós epistêmicos.

Os autorxs destacam-se como cientistas contra hegemônicos que optaram politicamente pela escolha de temas diretamente ligados às suas trajetórias de vida e luta política, entendias como indissociáveis. Juntos fazem ciência, assumindo o risco e a responsabilidade de construir conhecimento (re) elaborando as estruturas de produção do saber. Esses textos, falam conjuntamente sobre as mudanças do próprio fazer da ciência, decorrentes das transformações recentes do perfil das universidades públicas brasileiras. Este dossiê é um exercício insurgente de poder e é uma oportunidade, para acessar iniciativas de superações coloniais na produção do pensamento. Os textos são produzidos a partir de vivências em conflitos territoriais, luta por direitos e reconhecimento em um contexto de cooperação para a produção do conhecimento numa perspectiva decolonial.

O primeiro artigo, "O Laboratório de Filosofia Africana Geru Maã na UFRJ e os desafios para produção de conhecimento sobre filosofia africana e as relações raciais" de Katiúscia Ribeiro, apresenta uma panorama sobre a invisibilidade da filosofia africana e uma crítica a centralidade da razão ocidental através da implantação do Laboratório de Filosofia Africana Geru Maã na UFRJ, 
de forma crítica o texto aponta desafios para estudos sobre o racismo, as relações étnico-raciais e os desdobramentos dessas questões para profissionais da educação na perspectiva de adequação às exigências da lei 10639/03.

O sobre os processos de colonização, colonialidade e contra colonização e como influenciam o campo da saúde é objeto de reflexão do artigo, "Memórias de saberes tradicionais no antigo quilombo Cabula (Salvador - BA): percursos entre narrativas de parto", de autoria de Mary Lúcia Souto Galvão com coautoria de Ticiana Osvald Ramos, Maiara de França Gomes, Fernanda de Santana Barros e Francisca de Paula Santos da Silva. O texto apresenta uma discussão teórica e metodológica partindo do território quilombola do Cabula, ancorando no debate sobre aporta na incidência da colonização de saberes sobre o oficio das Parteiras Tradicionais e no contexto da gestação, parto e pós-parto, com destaque para as narrativas de parto humanizado como resistência contra colonização.

Em "A mulher na cidade: uma proposta metodológica para a análise do espaço urbano sob a perspectiva da Marcha Mundial de Mulheres na cidade de Salvador", Júlia Garcia de Souza da Silva apresenta os resultados de um estudo sobre metodologias de pesquisa para a análise do espaço urbano a partir da articulação da ciência geográfica e da epistemologia feminista socialista. O texto explora o nó que imbrica as relações sociais de sexo, raça/etnia e classe com o espaço geográfico. O texto centra a investigação nas proposições políticas do movimento Marcha Mundial de Mulheres para a cidade de Salvador, discutindo a importância da centralidade e a compreensão do olhar do movimento feminista para o direito à cidade.

O artigo, "Intelectuais negros(as) e negros(as) intelectuais: breve reflexão sobre o conceito" de autoria de Paulo Marcos Pereira, discute sobre o conceito de intelectual através das principais contribuições de autores clássicos para 0 debate sobre os intelectualidade, focando no uso do termo intelectual no sentido mais amplo e na complexidade e implicações do uso do termo intelectual no caso de pessoas negras, tratando ainda das variações encontrados na literatura consultada: intelectual negro, negro intelectual e negro-intelectual.

Uma reflexão sobre contradições e conflitos na trajetória do Movimento dos Atingidos por Barragens, MAB na região Oeste da Bahia, nas bacias dos rios Corrente e Carinhanha é apresentado por Andreia Neiva e Temóteo Gomes. $O$ texto "O Movimento dos Atingidos por Barragens/MAB na Bacia do Rio Corrente: lutas e resistências em defesa dos direitos das populações atingidas", analisa a luta e resistência e os processos de organização dos atingidos em defesa de seus direitos e do meio ambiente. O leitor poderá conhecer o histórico da formação do oeste da Bahia e algumas características que fazem dessa região um lugar de lutas e enfrentamentos entre camponeses e empresas capitalistas pelo uso e apropriação das terras e das águas, através da exploração pelas barragens e pelo agronegócio.

O trabalho de minha autoria e da pesquisadora Edleuza Barbosa tem por foco compreender o processo de nucleação da Escola Municipal Nossa Senhora Aparecida, na cidade de Bom Jesus da Lapa - BA. Em especial as estratégias de gestão e integração dos novos estudantes à comunidade escolar em um contexto de avanço do neoliberalismo na educação. O texto se direciona na reflexão crítica sobre os conflitos e desafios do processo de nucleação, tais como o deslocamento físico e simbólico dos estudantes das comunidades rurais e quilombolas. A partir das análises da pesquisa, é possível perceber que o 
processo de nucleação não contribui com o desenvolvimento do ensinoaprendizagem dos estudantes e cria novos problemas para os estudantes.

O artigo "Mobilização e representação: dinâmicas da participação social no jogo democrático em Juazeiro - Ba" de Cláudio Roberto dos Santos de Almeida, apresenta reflexões e de como a esfera pública tem sido constituída em Juazeiro e Petrolina (as duas cidades mais importantes do Sub-Médio São Francisco) a partir da atuação das associações organizadas em torno da experiência étnicoracial. O pano de fundo é a compreensão de como estas cidades florescem enquanto ambientes no quais se desdobram os processos interativos e identitários, direcionados à apresentação de demandas sociais ao poder público na região

Ana Paula Rodrigues analisa as formas de organização do movimento ambientalista na Bahia, refletindo sobre os desafios postos pelo o capitalismo neoliberal e as suas contradições para o desenvolvimento. $O$ artigo, "A luta ambientalista na Bahia: um estudo de caso sobre o Movimento pela soberania popular na mineração no alto sertão baiano" explora numa perspectiva panorâmica o texto faz um histórico sobreo movimento ambientalista brasileiro e a institucionalização da educação ambiental para compressão das formas de mobilização do movimento pela soberania popular na mineração no alto sertão baiano.

\section{REFERÊNCIAS}

GOHN, Maria da Glória. Abordagens teóricas no estudo dos movimentos sociais na américa latina. Cad. CRH [online]. 2008, vol.21, n.54, pp.439-455. ISSN 0103-4979. doi:10.1590/S0103-49792008000300003.

JAMOUNT, J. VARELLA R. A Pesquisa Militante na América Latina: trajetória, caminhos e possibilidades. Revista Diretiro \& Praxis. 2016, Vol. 07, N. 13, p. 414464 ISSN: 2179-8966 DOI: 10.12957/dep.2016.21833| 